\title{
Synthesis, reactivity and application studies for different biolubricants
}

\author{
Jumat Salimon*, Bashar Mudhaffar Abdullah, Rahimi M Yusop and Nadia Salih
}

\begin{abstract}
Vegetable oils have different unique properties owing to their unique chemical structure. Vegetable oils have a greater ability to lubricate and have higher viscosity indices. Therefore, they are being more closely examined as base oil for biolubricants and functional fluids. In spite of their many advantages, vegetable oils suffer from two major drawbacks of inadequate oxidative stability and poor low-temperature properties, which hinder their utilization as biolubricant base oils. Transforming alkene groups in fatty acids to other stable functional groups could improve the oxidative stability, whereas reducing structural uniformity of the oil by attaching alkyl side chains could improve the low-temperature performance. In that light, the epoxidation of unsaturated fatty acids is very interesting as it can provide diverse side chains arising from the mono- or di-epoxidation of the unsaturated fatty acid. Oxirane ring opening by an acid-catalyzed reaction with a suitable reagent provides interesting polyfunctional compounds.
\end{abstract}

\section{Introduction}

Oils and fats have recently been used in environment friendly processes to produce tailor-made products and in novel chemical reactions to functionalize the carbon chain for the synthesis of new compounds. Most of the current developments are in the areas of green chemistry, cleaner energy-saving processes, renewable resources, and enzymecatalyzed reactions [1]. Changing perceptions of what is nutritionally desirable in fat-based products also drives changing technology. Esterification is more widely used in the formulation of some modified fats [2].

Commercial oils and fats are mixtures of lipids. They are mainly triacylglycerols associated with diacylglycerols, monoacylglycerols, and free fatty acids in varying percentages. They may also contain phospholipids, free sterols and sterol esters, tocols, triterpene alcohols, hydrocarbons, and fat-soluble vitamins. The above description refers to the composition of crude oils when first extracted. During refining, some of the minor components are removed, wholly or in part, and useful materials may be recovered [3]. Each fat and oil molecule has a set of unique physical, chemical, and compositional parameters by which it can be recognized [4]. Traditional physical properties include

\footnotetext{
* Correspondence: jumat@ukm.my

School of Chemical Sciences \& Food Technology, Faculty of Science and Technology, Universiti Kebangsaan Malaysia, 43600 Bangi, Selangor, Malaysia
}

density, melting behavior, refractive index, and viscosity [3]. The chemical properties include iodine value, saponification value or saponification equivalent, acetyl value, acid value, and peroxide value. These properties depend on their fatty acid content.

\section{Review}

\section{Chemical structure of mineral and synthetic oils}

Fatty acids, the main constituent of oils and fats, esterified using glycerol. The industrial exploitation of oils and fats for both food and oleochemical products is based on the chemical modification of both the carboxyl and unsaturated groups present in fatty acids. Although the most reactive sites in fatty acids are the carboxyl groups and the double bonds, the methylene groups adjacent to these functional groups are also activated, increasing the reactivity of the fatty acid. Only rarely do saturated chains show reactivity [1]. Carboxyl groups and unsaturated centers usually react independently; however, when in close proximity, both may react through neighboring group participation. In enzymatic reactions, the reactivity of the carboxyl group can be influenced by the presence of a proximate double bond [5].

Fatty acids from various sources exhibit many common features. This is a consequence of similarities in the biosynthesis of fats and oils throughout the vegetable and animal kingdoms. Small variations result from changes in 
the synthesizing enzymes, which, in some cases, can now be explained in terms of their amino-acid sequence. The following generalizations are true for most common fatty acids and for many of the minor acids described below although there are exceptions, which are sometimes significant [3]:

1. Natural fatty acids, both saturated and unsaturated, are straight-chain compounds with an even number of carbon atoms.

2. Unsaturated acids are often olefinic and have the cis configuration.

3. Polyunsaturated acids generally have a methyleneinterrupted arrangement of cis-olefinic double bonds, such as that observed in linoleic acid. This pattern of unsaturation is characteristic of fatty acids, and is the cause for the characteristic reaction behaviour of fatty acids observed with oxygen, hydrogen, and alkalis.

4. Fatty acids rarely have functional groups other than the carboxyl group and the olefinic centers.

Nevertheless, the fatty acids are categorized according to the following groups: hydroxy, epoxy, keto, or halogen.

Mineral oils, however, are extremely complex mixtures of $\mathrm{C}_{20}-\mathrm{C}_{50}$ hydrocarbons containing a range of linear alkanes (waxes), branched alkanes (paraffinics), alicyclic (naphthenics), olefinic, and aromatic species. They also contain significant amounts of heteroatoms, mainly sulfur. Mineral oils are more stable, cheaper, and more readily available than natural oils, and are also available in a wider range of viscosities. However, one issue regarding mineral oils is that oils derived from different sources have different characteristics. Another issue regarding mineral oils is the volatilization of low-molecular-weight components, which leads to a tendency to thicken during use. The presence of low-molecular-weight components also reduces the flash point of mineral oils compared to natural oils of the same viscosity [6]. There are a range of synthetic lubricants such as polyolefins (PAOs) that have characteristics similar to highly refined paraffinic mineral oils, but with a narrower molecular weight distribution. Alkyl benzenes are a class of synthetic hydrocarbons; the lubricant industry, however, almost exclusively uses branched alkyl benzenes as they have better low-temperature fluidity [7].

Esters were originally developed for the lubrication of aircraft jet engines [8] but have subsequently found widespread use, particularly in applications where biodegradability is required. The presence of the ester group in lubricants confers low-temperature fluidity and reduces volatility at high temperatures. It also provides an affinity for metal surfaces [8]. For applications where chemical stability is an overriding requirement, non-hydrocarbon- based fluids such as poly(dimethyl siloxanes) and perfluoroalkyl ethers may be used. However, the use of these non-hydrocarbon-based biolubricants is restricted by their relatively high cost and their incompatibility with other biolubricants and standard additives. All synthetic biolubricants are normally used as formulations containing the same types of functional additives as are used in mineral oils [9]. Table 1 shows further information regarding the synthetic lubricants available in the market.

\section{Jatropha curcas seed oil}

$J$. curcas can grow well under adverse climatic conditions because of its low moisture demands, fertility requirements and tolerance to high temperatures [10]. It is easy to grow, grows relatively quickly, and is hardy (being tolerant to drought). However, it is not grown widely because its leaves and stems are toxic to animals; however, the seeds or seed cake can be used as an animal feed. Various parts of the plant are of medicinal value; its bark contains tannin, while its wood and fruit can be used for numerous purposes, including as fuel $[11,12]$.

The latex produced from the branches is useful for wound healing and other medical uses. Each fruit contains 2-3 oblong black seeds, which can produce oil. The seed kernel contains 40-60 wt\% of oil [13]. The extracted seed oil is useful for medicinal and veterinary purposes, as an insecticide, for soap production and as a fuel substrate [11]. The two principal objectives of studies such as these are to use oil plants and their products for economic and environmentally sustainable rural development and to make rural areas self-sufficient in energy, especially liquid fuels. Where possible, this is to be achieved without displacing other agricultural crops or competing for land that is more suitable for other applications. J. curcas was chosen as one of the prime plant oil species, especially from Brazil, Nepal, Malaysia and Zimbabwe. This study focuses on J. curcas seed oil because it is toxic and cannot be used for food consumption. Moreover, it has many industrial applications such as biodiesel, biolubricants, and polymers [12]. Studies on the physical and chemical characteristics of $J$. curcas seed oil are quite extensive.

A comparative evaluation of the physicochemical properties of J. curcas seed oil from Malaysia, Indonesia, and Thailand has been conducted previously [14]. Physicochemical properties such as the density, viscosity, fatty acid (FA)\%, iodine value, saponification value, and peroxide value of the $J$. curcas seed oil were evaluated. The evaluation of fatty acid composition revealed that the oleic (42.4-48.8\%) and linoleic acids (28.8-34.6\%) were the dominant fatty acids present in J. curcas seed oil. Saturated fatty acids such as palmitic and stearic acid were found to be present in the range of $4.5-13.25 \%$ and $7-$ $7.7 \%$, respectively. The major triacylglycerols (TAG) 
Table 1 Type and application of synthetic biolubricants [9]

\begin{tabular}{|c|c|c|c|c|c|c|}
\hline No. & Class & Type & $\begin{array}{c}\text { Operating } \\
\text { temperature }{ }^{\circ} \mathrm{C}\end{array}$ & Applications & $\begin{array}{l}\text { Advantages } \\
\text { vs. mineral oil }\end{array}$ & Limiting properties \\
\hline 1. & $\begin{array}{l}\text { Synthesized fluids } \\
\text { hydrocarbons (SFHs) }\end{array}$ & $\begin{array}{l}\text { Polyalphaolefins, } \\
\text { alkylated aromatics, } \\
\text { polybutenes, } \\
\text { cycloaliphatic }\end{array}$ & 155 to -45 & $\begin{array}{l}\text { Machine tool } \\
\text { spindles, } \\
\text { Freezer plants- } \\
\text { motors, con } \\
\text { veyors, bearings }\end{array}$ & $\begin{array}{l}\text { High temperature stability, long } \\
\text { life, low temperature fluidity, high } \\
\text { viscosity index, improved wear } \\
\text { protection, low volatility, } \\
\text { oil economy }\end{array}$ & $\begin{array}{l}\text { Solvency/detergency, } \\
\text { seal compatibility }\end{array}$ \\
\hline 2. & Organic esters & $\begin{array}{c}\text { Dibasic acid ester, } \\
\text { polyol ester }\end{array}$ & 204 to -35 & $\begin{array}{l}\text { Commercial } \\
\text { manual transmission }\end{array}$ & $\begin{array}{c}\text { No wax, high temperature } \\
\text { stability, long life, low } \\
\text { temperature fluidity, solvency/ } \\
\text { detergency }\end{array}$ & $\begin{array}{l}\text { Seal compatibility, mineral } \\
\text { oil compatibility, antiwear } \\
\text { and extreme pressure, } \\
\text { hydrolytic stability, paint } \\
\text { compatibility }\end{array}$ \\
\hline 3. & $\begin{array}{l}\text { Phosphate esters } \\
\text { (phosphoric } \\
\text { acid esters) }\end{array}$ & $\begin{array}{l}\text { Triaryl phosphate } \\
\text { ester, trialkyl } \\
\text { phosphate ester, } \\
\text { mixed alkylaryl } \\
\text { phosphate esters }\end{array}$ & 180 to -18 & Hydraulic Systems & $\begin{array}{l}\text { Fiber resistance, } \\
\text { lubricating ability }\end{array}$ & $\begin{array}{l}\text { Seal compatibility, low } \\
\text { viscosity index, paint } \\
\text { compatibility, metal } \\
\text { corrosion, hydrolytic stability }\end{array}$ \\
\hline 4. & Polyglycols & $\begin{array}{c}\text { Polyalkylene, } \\
\text { polyoxyalklylene, } \\
\text { polyethers, glycols }\end{array}$ & 245 to -20 & Gas turbines & $\begin{array}{c}\text { Water versatility, high viscosity } \\
\text { index, low temperature fluidity, } \\
\text { antirust, no wax }\end{array}$ & $\begin{array}{l}\text { Mineral oil compatibility, } \\
\text { paint compatibility, } \\
\text { oxidation stability }\end{array}$ \\
\hline
\end{tabular}

Source: Salimon et al. [9].

were observed to be oleic-oleic-linoleic (OOL) 22.94$25.75 \%$ and oleic-linoleic-linoleic (OLL) 15.52-20.77\%.

The kinetics of epoxidation of J. curcas seed oil by peroxyacetic or peroxyformic acid, formed in situ by the reaction of aqueous hydrogen peroxide and acetic/formic acid, in the presence of an acidic ion exchange resin as catalyst in or without toluene, was studied by [15]. The presence of an inert solvent in the reaction mixture appeared to stabilize the epoxidation product and minimize any side reaction, such as the opening of the oxirane ring. The effect of several reaction parameters such as stirring speed, hydrogen peroxide-to-ethylenic unsaturation molar ratio, acetic/formic acid-to-ethylenic unsaturation molar ratio, temperature, and catalyst loading on the epoxidation rate as well as on the oxirane ring stability and iodine value of the epoxidized $J$. curcas oil were examined. The multiphase process consisted of a consecutive reaction comprising an acidic ion exchange resin-catalyzed peroxyacid formation followed by epoxidation. The catalytic reaction of peroxyacetic/peroxyformic acid formation was found to be characterized by the adsorption of only acetic (or formic) acid and peroxyacetic/peroxyformic acid on the active catalyst sites, and the irreversible surface reaction was the overall rate determining step. The proposed kinetic model takes into consideration two side reactions, namely, epoxy ring opening involving the formation of hydroxyl acetate and hydroxyl groups and the reaction of the peroxyacid and epoxy group. The kinetic and adsorption constants of the rate equations were estimated by the best fit using the nonlinear regression method. Good agreement between experimental and predicted data validated the proposed kinetic model. Small values of kinetic rate constants for both the side reactions indicated that the ring-opening reactions were relatively much slower. The activation energy for the epoxidation reaction was determined to be $53.6 \mathrm{~kJ} / \mathrm{mol}$.

J. curcas seed oil and soybean oil have high a content of unsaturated fatty acids that can be converted to epoxy fatty acids, as reported by [16]. The plant oil-based epoxies are sustainable, renewable, and biodegradable materials that can replace petrochemical-based epoxy materials in some applications. To produce epoxidized soybean oil and epoxidized J. curcas seed oil, we carried out the epoxidation reaction using conventional chemistry at $50^{\circ} \mathrm{C}$ under atmospheric pressure for about $10 \mathrm{~h}$. The maximum reaction conversion was $83.3 \%$ for the epoxidation of soybean oil and $87.4 \%$ for the epoxidation of $J$. curcas seed oil. The presence of an excess amount of hydrogen peroxide was necessary in the reaction to achieve high reaction conversion. The highest epoxy content observed in epoxidized soybean oil was $6.13 \mathrm{wt}$ $\%$, which is comparable to the epoxy content in commercially available epoxidized soybean oil. The highest epoxy content observed in epoxidized $J$. curcas seed oil was $4.75 \mathrm{wt} \%$; unfortunately, there is no commercially available epoxidized $J$. curcas seed oil to make a comparison. It is possible to produce epoxidized J. curcas seed oil in Thailand as J. curcas seed oil is produced locally unlike soybean oil, which is imported. However, the applications of epoxidized J. curcas seed oil from Thailand are limited owing to its lower epoxy content, despite the oil extracts exhibiting good physicochemical properties. In contrast, the fatty acids of Malaysian $J$. curcas seed oil have a great potential in oleochemical applications such as surface coatings, biodiesels, and biolubricants. Therefore, it is pragmatic to carry out more research on Malaysian J. curcas seed oil and its fatty 
acids in the future to explore its potential for future industrial oilseed crops.

\section{Biolubricants}

The many terms that are used for the classification of biolubricants and their products include environmentally friendly, environmentally acceptable, biodegradable, and non-toxic. Approximately $1 \%$ of the total mineral oil consumed is used to formulate biolubricants [9]. Figure 1 reveals the worldwide market for biolubricants with altered physical properties and appearances [9]. Biolubricants that remain in the environment also include those used in circulation systems, which are not collected or disposed of. In addition, leaked biolubricants and those remaining in filters or containers have to be taken into account. Based on the above-mentioned statistic, it was determined that the environment in Germany is exposed to about 150,000 tons of biolubricants annually, which represents the volume of biolubricant that returns to the environment [17]. A calculation based on the actual biolubricant consumption in Germany and the disposal rates for different types of biolubricants reveal that the total volume of biolubricants could be about 250,000 tons annually. Consideration of the volume representing lost biolubricants and undefined biolubricants accounted for the total volume of biolubricants in Germany. It is likely that the volume of biolubricants returning to the environment may be in the order of at least $300000 \mathrm{t} / \mathrm{a}$ [18].

The production, application, and disposal of biolubricants have to meet safety guidelines in order to provide the best possible protection for the environment and living beings in particular. Most often, health hazards to humans are derived from indirect routes through the environment. For all cases of direct contact between biolubricants and human beings, compatibility has to be verified. All measures have to be taken to minimize damage to the environment. In evaluating the seriousness of the detrimental effects on the environment, the advantages of biolubricants, such as their performance or economic properties, must be considered and weighed against the risks associated with these biolubricants [19]. The term biolubricant applies to all biolubricants that are both rapidly biodegradable and non-toxic to humans and

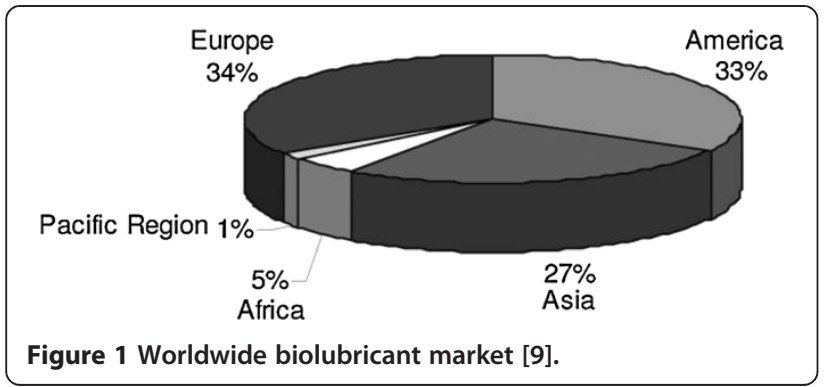

aquatic environments. A biolubricant may be vegetable oil-based such as rapeseed oil or derived from synthetic esters manufactured from modified renewable oils or from mineral oil-based products [20].

Typically, biolubricants designed for one application are not suitable for use in another application without a loss in performance. Equipment manufacturers play a predominant role in recommending viscosity grades and biolubricant quality based upon their system needs. Biolubricant properties that are commonly considered for assessing the suitability of a biolubricant for a particular application include the fluidity range, viscosity index, low-temperature fluidity, oxidation stability (inhibited), hydrolytic stability, thermal stability, mineral oil compatibility, additive solvency, volatility, rust control (inhibited), boundary lubrication, fire resistance, elastomer compatibility (especially with buna rubber), and relative cost [21]. Additional properties that are important in some other applications include color, density, volatility, bulk modulus, shear stability, acidity and alkalinity, detergency, and foaming and air release tendency [21]. Current research efforts are directed towards improving the low-temperature stability of vegetable oils by chemical modification, blending with functional fluids, and by the use of additives. The main properties to take into account are as follows:

\section{a. Pour Point}

For proper lubrication of mechanical equipment, petroleum-based biolubricants that operate in the liquid phase have been designed. Accordingly, for a base stock, it is important to know the temperature at which the transition between the liquid and solid phases occurs and manufacture it to be as low as necessary. This temperature is known as the pour point (PP) and is defined as the lowest temperature at which movement of the specimen is observed [22]. PP values have traditionally been measured when the sample no longer moves on tilting the tube containing the sample (pour point). Pour points lower than $0^{\circ} \mathrm{C}$ are considered to be low [3].

b. Flash Point

The flash point is defined as the minimum temperature at which a liquid produces a sufficient concentration of vapor above it to form an ignitable mixture with air. Oils with a lower flash point are a greater fire hazard. The flash point should be high enough to allow safe operation and minimum volatilization at the maximum operating temperature. For the most demanding applications, such as aviation jet engine biolubricants, an effective liquid range over $300^{\circ} \mathrm{C}$ may be required [9].

c. Viscosity

The viscosity of fatty acids and vegetable oils is a quantitative measure of its resistance to flow. It is 
the key property of base stocks since it is a major factor in determining their application; for example, low viscosity stocks can be used for automotive transmission oils, while higher viscosity stocks are employed in diesel engine oils. Base stocks are usually named according to their viscosity. Viscosity measurements on base stocks assume that the liquids are Newtonian in which shear stress and shear rate are linearly related [22]. Viscosity is critical to determining the quality of a biolubricant film. In metal forming applications, the biolubricant viscosity determines the effectiveness of the film in separating the tool from the work-piece, thereby controlling friction and wear. Metal removal operations, on the other hand, have diverse lubrication needs, and, hence, the optimum biolubricant viscosity must be estimated for each operation. This is accomplished by considering the ability of the biolubricant to enter and remain in the contact zone, the durability of the biolubricant film, the desired rate of spreading, and its cooling capability [21].

d. Oxidative Stability

Oxidation is the most important reaction of oils resulting in increased acidity, corrosion, viscosity, and volatility when biolubricant-based oils are used as engine oils. The triacylglycerol structure forms the backbone of most available vegetable oils that comprise different fatty acid chains. Therefore, a complex association of different fatty acid molecules attached to a single triacylglycerol structure constitutes a vegetable oil matrix. The presence of unsaturation in the triacylglycerol molecule, owing to the presence of oleic, linoleic, and linolenic acid moieties, functions as the active site for various oxidation reactions. Saturated fatty acids have relatively high oxidation stability, which decreases with increasing unsaturation in the molecule [23]. Several oxidation tests are available primarily as screening tools for oxidative stability of fatty acids and vegetable oils. The evaluation of oxidation is extremely complex, and a fully acceptable protocol is yet to emerge [24].

The direct use of vegetable oils as biolubricants has disadvantages because of a variety of factors. Vegetable oils have poor oxidative and thermal stability due to the presence of acyl groups. The presence of the glycerol backbone in oil gives rise to a tertiary $\beta$-hydrogen, which is thermally unstable. Fortunately, there are different ways and methods to overcome it. For example, the chemical modification of vegetable oils by reactions such as epoxidation, esterification, and acetylation across the double bonds constitutes a promising method for obtaining valuable commercial products from renewable raw materials [9].
In order to use vegetable oil with special additives such as antioxidants, viscosity modifiers, rust inhibitors, wear reducers, pour point depressors (PPD), de-emulsifiers, and hydrolysis inhibitors to improve biolubricant properties, chemical modifications, de novo synthesis, breeding and biotechnology play an important role. These methods improve the performance and stability of base oils in lubricating formulations. They also allow the use of vegetablebased oil substrates for green engineering [9]. Chemical modifications such as epoxidation, oxirane ring opening, and esterification of vegetable oils have been shown to improve the PP, flash point, viscosity and oxidative stability of the vegetable oilbased biolubricants and to achieve optimal characteristics for extreme applications [25].

\section{Epoxidation reaction}

Epoxides are produced by the reaction of double bonds with peracids. This proceeds by a concerted mechanism, giving cis stereospecific addition. Thus, a cis olefin leads to a cis epoxide and a trans-olefin to a trans-epoxide. The carboxylic acid produced is a stronger acid than the strongly hydrogen bonded peracid and may lead to subsequent ring opening reactions, especially in the case of formic acid. Small-scale reactions are carried out using $\mathrm{m}$-chloroperbenzoic acid in a halocarbon or aromatic solvent in the presence of bicarbonate to neutralize the carboxylic acid as soon as it is formed [26]. Epoxides are highly reactive and readily undergo ring-opening reactions in acid following protonation of the epoxy oxygen (Figure 2). This is a route commonly employed for the synthesis of diols and polyols that are used in the production of polymers and a range of hydroxyl compounds. Ring opening of methylene-interrupted di-epoxides leads to the formation of 5- and 6-membered ring ethers through neighboring group participation [26]. Many studies have indicated the importance of using catalysts for epoxidation purposes.

The epoxidation of Mahua oil (Madhumica indica) by hydrogen peroxide was studied by [27]. Mahua oil with an iodine value of $88 \mathrm{~g} / 100 \mathrm{~g}$, and containing $46 \%$ oleic acid and $12.74 \%$ linoleic acid, was epoxidized in situ with hydrogen peroxide as an oxygen donor and glacial acetic acid as an active oxygen carrier in the presence of a catalytic amount of an inorganic acid. Higher temperatures and higher sulfuric acid concentrations reduced the reaction time and resulted in higher oxirane content with less cleavage to glycol. $\mathrm{H}_{2} \mathrm{SO}_{4}$ was found to be more effective in terms of oxirane conversion. The epoxidation reaction of mahua oil fell into a kinetically controlled regime at stirring speeds $>1500 \mathrm{rev} / \mathrm{min}$. From the relative conversion data obtained for various reaction parameters, it can be concluded that it is possible to develop value added products, such as epoxides, from Mahua oil. 


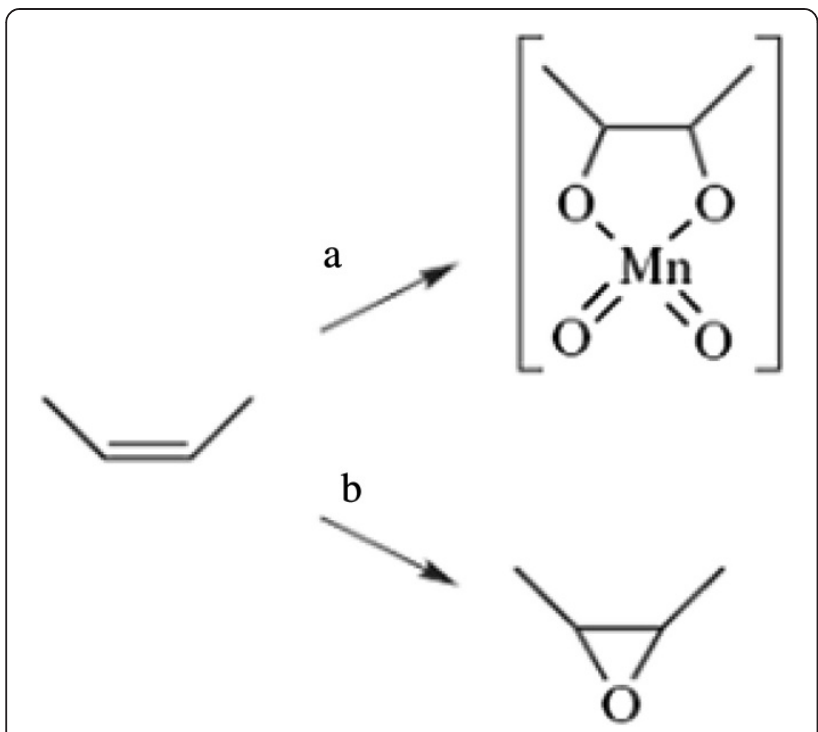

Figure 2 Stereochemistry of epoxidation reactions with $\mathrm{KMnO}_{4}$ (a); m-chloroperbenzoic acid (b) catalyzed hydrolysis [26].

A study of the epoxidation of soybean oil and soybean methyl esters with a dilute solution of hydrogen peroxide (6 wt\%) using an amorphous heterogeneous $\mathrm{Ti} / \mathrm{SiO}_{2}$ catalyst in the presence of tert-butyl alcohol was studied by [28]. The highest yields of epoxidized olefins were obtained on using a $\mathrm{H}_{2} \mathrm{O}_{2}$ : substrate molar ratio of 1:1. Ratios higher than this were not effective in speeding up the reaction. The parameters affecting the lipase activity and operational lifetime of the chemo-enzymatic epoxidation of fatty acids (oleic acid, palmitic acid, and epoxystearic acid) by immobilized Candida antarctica lipase

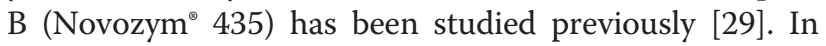
the presence of 6-12 $\mathrm{M}$ hydrogen peroxide, the enzyme was rather stable at $20^{\circ} \mathrm{C}$, while at $60^{\circ} \mathrm{C}$, the enzyme lost activity rapidly, with the rate of deactivation increasing with hydrogen peroxide concentration. In the work presented here, the parameters found to be most crucial for the activity and, hence, the operational stability of Novo$\mathrm{zym}^{\circ} 435$ in the chemo-enzymatic epoxidation of fatty acids, were the high concentration of hydrogen peroxide and elevated temperatures. For epoxidation processes run at elevated temperatures, the controlled addition of $\mathrm{H}_{2} \mathrm{O}_{2}$ is important for enzyme stability, more so in the initial stages of the reaction, where the formation of water is sufficient to dilute the added $\mathrm{H}_{2} \mathrm{O}_{2}$. Since the reaction is exothermic, a large-scale process would probably be most efficient if a temperature program is used. Concurrent with improving the process design, development of a more stable biocatalyst preparation would be an alternative strategy.

Canola oil, with an iodine value of 112/100 g, and containing $60 \%$ oleic acid and $20 \%$ linoleic acid, was epoxidized using a peroxyacid generated in situ from hydrogen peroxide and a carboxylic acid (acetic or formic acid) in the presence of an acidic ion exchange resin (AIER), Amberlite IR 120H [30]. Acetic acid was found to be a better oxygen carrier than formic acid, as it resulted in about $10 \%$ more conversion of the ethylenic unsaturation to oxirane than that produced by formic acid under otherwise identical conditions. The parameters optimized were temperature $\left(65^{\circ} \mathrm{C}\right)$, acetic acid to ethylenic unsaturation molar ratio (0.5), hydrogen peroxide to ethylenic unsaturation molar ratio (1.5), and AIER loading (22\%). An iodine conversion of $88.4 \%$ and a relative conversion to oxirane of $90 \%$ were obtained under the optimum reaction conditions. The heterogeneous catalyst, AIER, was found to be reusable and exhibited a negligible loss in activity.

Another study attempted to show the efficiency of epoxidation under different catalysts conditions [31]. It was found that different catalysts have been used for the epoxidation of oil and unsaturated fatty acids with almost complete conversion to form the monoepoxide of the unsaturated carbon. Catalysts such as $\mathrm{H}_{2} \mathrm{SO}_{4}, \mathrm{Ti}(\mathrm{IV})$ grafted silica catalysts, tungsten-based catalysts, acidic ion-exchange resins, potassium peroxomonosulfate, and alumina catalysts have been studied. $\mathrm{H}_{2} \mathrm{SO}_{4}$ was found to be more effective in terms of the complete conversion of oxirane. The epoxidation of oils and unsaturated fatty acids is widely used for the production of oxiranes, which are valuable industrial products that provide an access to various important chemicals; unfortunately, none of them have found an industrial application as yet.

The effect of reaction parameters on the lipase-mediated chemo-enzymatic monoepoxidation of linoleic acid was investigated by [32]. Hydrogen peroxide was found to have the most significant effect on the reaction rate and degree of epoxidation. An excess of hydrogen peroxide with respect to the unsaturation was necessary in order to yield total conversion within a short time period, as well as to compensate for hydrogen peroxide decomposition at temperatures above $50^{\circ} \mathrm{C}$. The reaction rate also increased with hydrogen peroxide concentration (between 10 and $50 \mathrm{wt} \%$ ), albeit at the expense of enzyme inactivation. Linoleic acid was completely epoxidized when used at a concentration of $0.5-2 \mathrm{M}$ in toluene at $30^{\circ} \mathrm{C}$, while in a solvent-free medium, the reaction was not complete due to the formation of a solid or a highly viscous oily phase, creating mass transfer limitations. Increasing the temperature up to $60^{\circ} \mathrm{C}$ also improved the rate of epoxide formation.

The monoepoxidation of methyl linoleate was examined using transition metal complexes as catalysts [33]. With a catalytic amount of methyltrioxorhenium (MTO) $4 \mathrm{~mol} \%$ and pyridine, methyl linoleate was completely epoxidized by aqueous $\mathrm{H}_{2} \mathrm{O}_{2}$ within $4 \mathrm{~h}$. Longer reaction times $(6 \mathrm{~h})$ were needed with $1 \mathrm{~mol} \%$ catalyst loading. Manganese tetraphenylporphyrin chloride was found to catalyze the partial epoxidation of methyl linoleate. A 
monoepoxidized species was obtained as the major product (63\%) after $20 \mathrm{~h}$.

Linoleic acid (LA) is converted to per-carboxylic acid, catalyzed by an immobilized lipase from Candida antarctica (Novozym 435) [34]. This per-carboxylic acid is only an intermediate, which undergoes self-epoxidation in good yields and almost without consecutive reactions. Reactions conditions for the monoepoxide linoleic acid 9(12)10(13)-monoepoxy 12(9)-octadecanoic acid (MEOA) was optimized using D-optimal design. Under optimum conditions, higher yields $(82.14 \%)$ and medium oxirane oxygen content (OOC) (4.91\%) of MEOA were predicted at $15 \mu \mathrm{L}$ of $\mathrm{H} 2 \mathrm{O} 2,120 \mathrm{mg}$ of Novozym 435, and $7 \mathrm{~h}$ of reaction time. In order to develop better quality biolubricants, we determined the pour point (PP), flash point (FP), viscosity index (VI), and oxidative stability (OT) for LA and MEOA. The results showed that MEOA exhibited good low-temperature behavior with a PP of $-41^{\circ} \mathrm{C}$. The FP of MEOA increased to $128^{\circ} \mathrm{C}$ comparing with $115^{\circ} \mathrm{C}$ of LA. Similarly, the VI for LA was 224, several hundred centistokes (cSt) more viscous than MEOA, which had a VI of 130.8. The ability to resist oxidative degradation is another important property for biolubricants. Therefore, LA and MEOA were screened to measure their OT, which was observed at 189 and $168^{\circ} \mathrm{C}$, respectively.

Recent studies have attempted to improve the efficiency of monoepoxidation under milder conditions by minimizing the formation of by-products. The lipase is remarkably stable under the reaction conditions and can be recovered and reused 15 times without loss of activity.

\section{Oxirane ring-opening reaction}

Because of the high reactivity of the oxirane ring, the epoxidation of the double bonds opens up a wide range of reactions that can be carried out under moderate reaction conditions. A variety of chemical modifications of epoxidized vegetable oils and fatty acids are possible through epoxy moiety, and one of the most commonly used is the ring-opening reaction [35].

Ring opening takes place through cleavage of one of the carbon-oxygen bonds. It can be initiated by either electrophiles or nucleophiles, or catalyzed by either acids or bases. For example, the acid-catalyzed hydrolysis of an epoxide is a useful procedure for preparing vicinal-dihydroxy compounds (glycols) [36]. The nucleophilic addition of a carboxyl group to the epoxide center can easily be promoted by protonation using solid acid catalysts (Figure 3 ). Nonetheless, the rate of the oxirane ring opening of epoxidized fatty acids strongly depends on the nature and structure of the carboxylic acid [37].

Acid catalysis assists epoxide ring opening by providing a better leaving group (an alcohol) at the carbon undergoing nucleophilic attack. This catalysis is especially important if the nucleophile is a weak one such as water or an alcohol. In the absence of an acid catalyst the leaving group must be a strongly basic alkoxide ion; however, such a reaction is not very environmentally friendly. Although such reactions do not occur with other ethers, they are possible with epoxides, provided the attacking nucleophile is strong enough [36]. There have been many studies on oxirane ring opening using different alcohols, catalysts, and carboxylic acids, as will be described in the following few paragraphs.

9,12-hydroxy-10,13-oleioxy-12-octadecanoic acid was synthesized based on the esterification reaction of monoepoxide linoleic acid 9(12)-10(13)-monoepoxy 12 (9)-octadecanoic acid (MEOA) with oleic acid (OA) and catalyzed by $p$-toluenesulfonic acid (PTSA) $[38,39]$. The optimum conditions for the experiment using D-optimal design to obtain high yield\% of 84.61, conversion\% of 83.54 and lowest $\mathrm{OOC} \%$ of 0.05 were predicted at an OA/MEOA ratio of 0.2:1 ( $\mathrm{mol} / \mathrm{mol})$, PTSA/MEOA ratio of $0.4: 1(\mathrm{~mol} / \mathrm{mol})$, reaction temperature of $110^{\circ} \mathrm{C}$, and reaction time of $4.5 \mathrm{~h}$. The results showed that an increase in the chain length of the mid-chain ester resulted in a decrease of the pour point to $-51^{\circ} \mathrm{C}$, an increase in the viscosity index up to 153 , and an improvement in the oxidative stability to $180.94^{\circ} \mathrm{C}$.

The degradation of the oxirane ring of epoxidized vegetable oils with hydrogen peroxide using an ion exchange resin (Amberlite IR-120) was done in a previous study [40]. The results showed that the ring opening increases either by adding a higher amount of catalyst to the system or by decreasing the particle size of the catalyst since, in both cases, the external area of the catalyst becomes larger. Despite the unavoidable presence of surface-exposed protons, the degradation can be reduced by several orders of magnitude for similar process conditions by using such a heterogeneous catalyst instead of mineral acids. Although the use of such ion exchange resins does not completely eliminate the attack on the oxirane group by $\mathrm{H}_{2} \mathrm{O}_{2}$ during the epoxidation process, this deleterious reaction only seems to be important under extreme process conditions, such as high temperature, excessive concentration of $\mathrm{H}_{2} \mathrm{O}_{2}$, and high molar ratio of $\mathrm{H}_{2} \mathrm{O}_{2}$ to double bonds, which are not common in industrial practice.

Another study focused on the main oxirane ring-opening reactions that occur during the manufacture of epoxidized vegetable oils using a strongly acidic, gel-type ion exchange resin (IER) (Amberlite IR-120, 8\% cross linking) [41]. The combined results on the attack on the oxirane ring of epoxidized vegetable oils by either $\mathrm{H}_{2} \mathrm{O}_{2}$ or solvated acetic acid indicate that under process conditions, these attacks proceed in the kinetic regime; that is, they are not masstransfer controlled. These results indicate that most of the degradation occurs on the catalyst and confirm that the external surface protons of the IER are mainly responsible for the deleterious degradation of the oxirane ring, since, 


\section{Epoxide activation:}

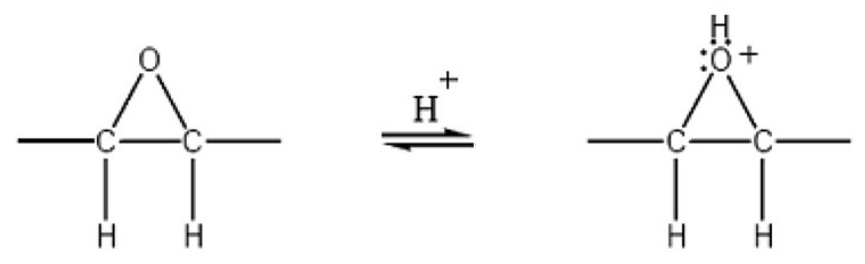

Nucleophilic attack:

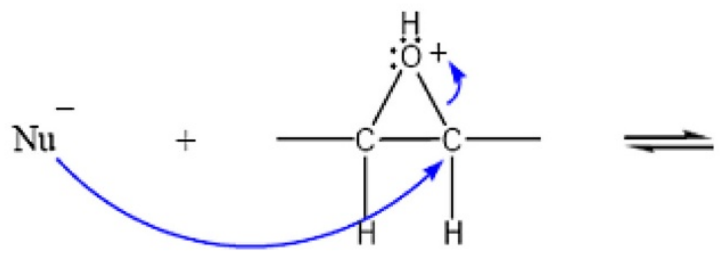

Figure 3 Acid catalyzed nucleophilic attack on an epoxide [36].

in both cases, the degradation rate was directly proportional to the available external area of the catalyst.

The ring-opening reaction of epoxidized soybean oil with different alcohols such as $n$-butanol, iso-amyl alcohol and 2-ethylhexanol was carried out in the presence of Amberlyst 15 (Dry) as a catalyst [42]. The observed pour points of the products were in the range of -5 to $-15^{\circ} \mathrm{C}$. The hydroxy group of the ring-opening product of $n$-butanol further reacted with acetic anhydride in the presence of Amberlyst 15 (Dry), which was previously used to carry out ring-opening reaction by alcoholysis. Oxirane ring opening was achieved using different alcohols and different carboxylic acids. Thus, these studies show that the high cleavage of the oxirane ring depends on the type of catalyst and on temperature.

\section{Esterification reaction}

Fatty acids are converted to esters through a reaction with excess of alcohol using an acid catalyst or lipase. Boron trifluoride, sulfuric acid, or anhydrous hydrogen chloride in methanol are commonly used for preparing methyl esters [43]. The reaction is completed in 30 minutes at reflux. Propyl and butyl esters are prepared similarly with the corresponding alcohols. Excess alcohol cannot always be used, for example, in the synthesis of triacylglycerols using a protected glycerol. A more reactive fatty acid derivative such as the acid chloride or anhydride is used, or the fatty acid reacts directly with the alcohol, using dicyclohexylcarbodiimide and 4-dimethylaminopyridine as a coupling agent, for example, in the synthesis of acylglycerols. Some groups in more uncommon fatty acids are acid sensitive, for example, epoxides, cyclopropanes, cyclopropenes, and hydroxy compounds, and hence, methods that do not involve acids catalysts are needed. Reaction with diazomethane or the less-hazardous trimethylsilyldiazomethane is possible [43]. Many studies have been carried out on the esterification process using different catalysts and alcohols.

A previous study focused on the esterification reaction of fusel oil and oleic acid, in which immobilised Novozym $435^{\circ}$ lipase enzyme was used as a biocatalyst [44]. Compared to the product obtained by acid catalysis, in the esterification reaction, there was no trace of oleic acid since the entire conversion was achieved by continuous water removal through evaporation. The results showed that the method could achieve 99.8\% conversion under optimal conditions. The oleochemical ester produced does not have aquatic toxicity and the determined tribological and physicochemical properties of the biolubricant proved that it is an environmentally friendly product.

Several diesters have been prepared from commercially available oleic acid and common organic acids [45]. The key step in the three-step synthesis of oleochemical diesters involves the ring-opening esterification of alkyl 9,10epoxyoctadecanoates, such as propyl, isopropyl, octyl, and 2-ethylhexyl, using propionic and octanoic acids without the need for solvents or catalysts. The increasing chain length of the mid-chain ester and branching in the endchain ester was found to have a positive influence on the low-temperature properties of the diester. Improved oxidation stability is achieved when the chain length of the mid-chain ester is increased. Additionally, the mid-chain ester plays a larger role in oxidation stability than the endchain ester. These products may prove useful in the search for bio-based industrial materials, such as biolubricants, surfactants, and fuel additives. 


\section{Polyester synthesis}

Biodegradable organic polyesters derived from the esterification of vegetable oils and branched neopolyols such as trimethylolpropan (TMP) and PE have been developed for various applications (Figure 4). In a previous study, biodegradable TMP 2-ethyl- 2-hydroxymethyl-1,3-propanediol esters of rapeseed oil fatty acids were synthesized using enzymatic and chemical methods [46]. Sodium methylate $(0.5 \% \mathrm{w} / \mathrm{w})$ was employed as a catalyst, and the reaction mixture was refluxed under a reduced pressure of $3.3 \mathrm{kPa}$. Approximately $99 \%$ of conversion was achieved at $110-120^{\circ} \mathrm{C}$ in $10 \mathrm{~h}$. By using $40 \% \mathrm{w} / \mathrm{w}$ Candida rugosa lipase, only $64 \%$ of the TMP was converted to triester in $24 \mathrm{~h}$ at $5.3 \mathrm{kPa}$ at $47^{\circ} \mathrm{C}$. With immobilized Rhizomucor miehei $(50 \% \mathrm{w} / \mathrm{w})$, the highest conversion to the TMP triester was $90 \%$ in $66 \mathrm{~h}$.

Another study demonstrated that palm oil TMP esters containing $98 \% \mathrm{w} / \mathrm{w}$ triester can be successfully synthesized in less than an hour [47]. The chemical transesterification of TMP with palm oil methyl esters was achieved under a reduced pressure of at least $20 \mathrm{mbar}$ at $120^{\circ} \mathrm{C}$ with a molar ratio 3.9:1 using sodium methoxide as a catalyst. The optimum molar ratio was established as 3.9:1, and less than $1.0 \% \mathrm{w} / \mathrm{w}$ of the catalyst was required, which is much lower than the lipase required for enzymatic transesterification $(40-50 \% \mathrm{w} / \mathrm{w})$ [48].

Esters of neopentylpolyols have also been prepared by an esterification reaction between $\mathrm{PE}$ and erucic acid catalyzed by PTSA in xylenes [49]. The reaction mixture was heated to $200^{\circ} \mathrm{C}$ under a nitrogen atmosphere. Since PE forms the backbone of the new esters, four types of esters were obtained, including tetra-, tri-, di-, and monoesters. These esters provided improved low-temperature behaviour. Animal fats have also been used to synthesize polyol esters using calcium methoxide; however, the rate of the reaction was slow. The yield of the reaction was $85-90 \%$ after $20 \mathrm{~h}$ [50]. A two-stage low-temperature crystallization process was used to improve the PP.

Another study demonstrated the use of functionalization to overcome these disadvantages [51]. In this work, mono-, tri- and tetra-esters were synthesized, including 10,12-dihydroxy-9 (stearoyloxy) octadecanoic acid 3; 9,10,12-tris(stearoyloxy)octadecanoic acid 4; and 18-(4ethylhexyloxy)-18-oxooctadecane-7,9,10- triyl tristearate 5. Pour-point and cloud-point measurements showed that these derivatives have improved low-temperature properties as compared to the precursor. The tetraester compound, 18-(4-ethylhexyloxy)-18-oxooctadecane-7,9,10-triyl tristearate 5 , had the lowest pour point of $-44.37^{\circ} \mathrm{C}$ and the lowest cloud point of $-41.25^{\circ} \mathrm{C}$. This derivatization also improved the compound's thermo-oxidative stability, measured using pressurized differential scanning calorimetry (PDSC) and thin-film micro-oxidation (TFMO) testing. 18(4-ethylhexyloxy)-18-oxooctadecane-7,9,10-triyl tristearate 5 also had the highest onset temperature (OT) $\left(282.10^{\circ} \mathrm{C}\right)$ and the lowest volatile loss and insoluble deposit (37.39\% and $50.87 \%$, respectively). Furthermore, the tribological behaviors of the compounds were evaluated using the four-ball method. 18-(4-ethylhexyloxy)-18-oxooctadecane7,9,10-triyl tristearate 5 also had the lowest coefficient of friction $(\mu)(0.44)$. The results showed that, in general, these derivatives exhibit good anti-wear and friction-reducing properties at relatively low concentrations, under all considered test loads.

Oleyl 9(12)-hydroxy-10(13)-oleioxy-12(9)-octadecanoate has been synthesized based on the esterification reaction of 9,12-hydroxy-10,13-oleioxy-12-octadecanoic acid with oleyl alcohol and catalyzed by sulfuric acid [52,53]. The following were considered optimum conditions to obtain high yield\%: OL/HYOOA ratio of $2: 1 \mathrm{~mol} / \mathrm{mol}$, SA/ HYOOA ratio of $0.7: 1 \mathrm{~mol} / \mathrm{mol}$, reaction temperature of $110^{\circ} \mathrm{C}$, and reaction time of $7 \mathrm{~h}$. Under these conditions, the yield was $88.7 \%$. The physicochemical characteristics were also determined, which showed improved lowtemperature $\left(-62^{\circ} \mathrm{C}\right)$ properties, viscosity index of 192 , and increased oxidative stability up to $215^{\circ} \mathrm{C}$.

\section{Conclusions}

Vegetable bio-based oils are an important part of developing new strategies, policies, and subsidies that aid in reducing the dependence on mineral oil and other nonrenewable sources. Vegetable oils exhibit unique chemical structures, and hence, their properties differ from those of mineral oils. By chemically modifying vegetable

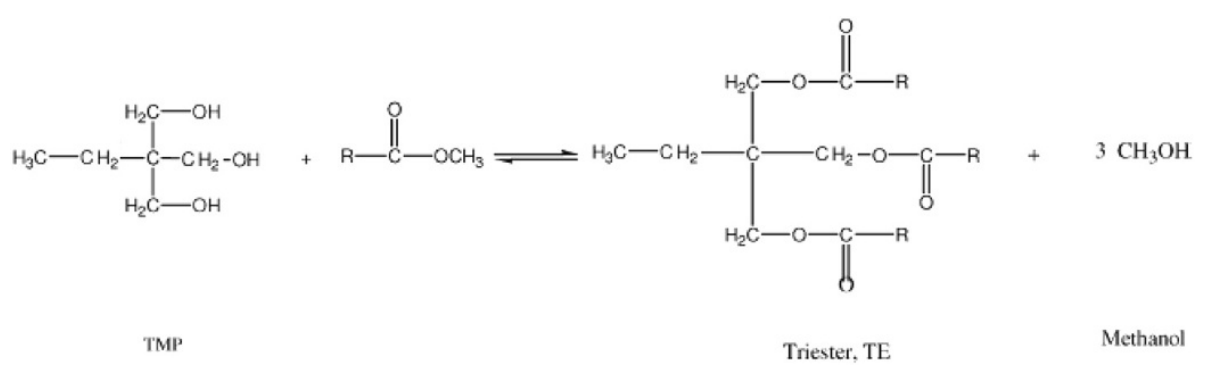

Figure 4 Trimethylolpropan esterification [46]. 
oils (through reactions such as epoxidation, esterification, and acetylation), their characteristics such as sensitivity to hydrolysis and oxidative attacks, low-temperature properties, and viscosity index coefficients can be improved. Chemically modified vegetable oils exhibit better lubrication ability, viscosity indices, and superior anticorrosion properties, because of the improved affinity of vegetable oils to metal surfaces. Vegetable oils can be used in an extremely wide range of automotive and industrial applications. Nonetheless, identifying a biolubricant that is both cost-effective and environment-friendly would be a challenge.

\section{Competing interests}

The authors declare that they have no competing interests.

\section{Authors' contributions}

BMA \& JS developed the concept analyzed the data and drafted the manuscript. RMY provided advice on the testing methods. NS performed the characterization methods. All of the authors read and approved the final manuscript.

\section{Acknowledgements}

The authors would like to thank Universiti Kebangsaan Malaysia for research grant UKM-AP-2011-17, DPP-2013-045, DL/2013/002 and FRGS/1/2012/ST01/ UKM/02/1 for financial support and technical assistance on this work.

Received: 17 July 2013 Accepted: 4 March 2014

Published: 10 March 2014

\section{References}

1. Akoh CC, Min DB: Food lipids: Chemistry, Nutrition, and Biotechnology. 2nd edition. New York: Marcel Dekker, Inc; 2002.

2. Gunstone FD, Padley FB: Lipid Technologies and Applications. New York: Marcel Dekker; 1997.

3. Gunstone FD: The Chemistry of Oils and Fats: Sources, Composition, Properties, and Uses. Oxford, UK: Blackwell publishing Ltd. CRC Press; 2004.

4. Gunstone FD, John LH, Fred BP: The Lipid Hand Book. 2nd edition. United States: New York: Chapman \& Hall; 1994

5. Knothe G, Derksen JTP: Recent Developments in the Synthesis of Fatty Acid Derivatives. Champaign, Illinois: AOCS Press; 1999.

6. Erhan SZ: Vegetable Oils as Lubricants, Hydraulic Fluids, and Inks. In Bailey's Industrial Oil and Fat Products. sixthth edition. Edited by Shahidi F. Hoboken, NJ: John-Wiley \& Sons Inc; 2005.

7. Warner JC, Cannon AS, Dye KM: Environmental impact assessment review. Green Chem 2004, 24:775-799.

8. Asadauskas S, Erhan SZ: Depression of pour points of vegetable oils by blending with diluents used for biodegradable lubricants. J Am Oil Chem Soc 1999, 76:313-316.

9. Salimon J, Salih N, Yousif E: Biolubricants: raw materials, chemical modifications and environmental benefits. Eur J Lipid Sci Technol 2010, 112:519-530.

10. Kaushik N, Kumar K, Kumar S, Kaushik N, Roy S: Genetic variability and divergence studies in seed traits and oil content of Jatropha (Jatropha curcas L.) accessions. Biomass Bioenergy 2007, 31:497-502.

11. Gübitz GM, Mittelbac M, Trabi M: Biofuels and Industrial Products from Jatropha Curcas. Managua, Nicaragua: Symposium 'Jatropha 97'; 1997.

12. Openshaw K: A review of Jatropha curcas: an oil plant of unfulfilled promise. Biomass Bioenergy 2000, 19:1-15.

13. Makkar HPS, Becker K, Sporer F, Wink M: Studies on nutritive potential and toxic constituents of different provenances of Jatropha curcas. J Agricul Food Chem 1997, 45:3152-3157.

14. Emil A, Zahira Y, Kumar MNS, Jahim JM, Salimon J: Comparative evaluation of physicochemical properties of Jatropha seed oil from Malaysia, Indonesia and Thailand. J Am Oil Chem Soc 2010, 87:689-695.

15. Goud W, Patwardhan AV, Dinda S, Pradhan NC: Kinetics of epoxidation of jatropha oil with peroxyacetic and peroxyformic acid catalysed by acidic ion exchange resin. Chem Eng Sci 2007, 62:4065-4076.
16. Meyer P-P, Techaphattana N, Manundawee S, Sangkeaw S, Junlakan W, Tongurai C: Epoxidation of soybean oil and Jatropha oil. Thammasat Int J Sci Technol 2008, 13:1-5.

17. Wagner $H$, Luther $R$, Mang $T$ : Lubricant base fluids based on renewable raw materials their catalytic manufacture and modification. App/ Catal $A$ Gen 2001, 221:429-442.

18. Levizzari A, Voglino M, Volpi P: Environmental and economic impact of re-refined produts: a life cycle analysis. Brussels: Proceedings of the 6th International LFE congress; 1999.

19. Kržan B, Vižintin J: Ester based lubricants derived from renewable. Res Tribol Indust 2004, 26:58-62.

20. Dorinson A, Ludema KC: Mechanics and Chemistry in Lubrication Amsterdam: Elsevier; 1985.

21. Rizvi SQA: A Comprehensive Review of Lubricant Chemistry, Technology, Selection, and Design. West Conshohocken: ASTM International; 2009.

22. Lynch TR: Process Chemistry of Lubricant Base Stocks. United States of America: CRC Press; 2008

23. Brodnitz MH: Autoxidation of saturated fatty acids. A review. J Agric Food Chem 1968, 16:994-999.

24. Labuza TP: Kinetics of lipid oxidation in foods. CRC Critical Rev Food Sci Technol 1971, 2:355-405.

25. Sharma BK, Adhvaryu A, Liu Z, Erhan SZ: Chemical modification of vegetable oils for lubricants applications. J Am Oil Chem Soc 2006, 83:129-136.

26. Karlson KD, Kleiman R, Bagby MO: Epoxidation of lesquerella and limnanthes (meadowfoam) oils. J Am Oil Chem Soc 1994, 71:175-182.

27. Goud W, Patwardhan AV, Pradhan NC: Studies on the epoxidation of mahua oil (Madhumica indica) by hydrogen peroxide. Bioresour Technol 2006, 97:1365-1371.

28. Campanella A, Baltanas MA, Capel-Sanchez MC, Campos-Martin JM, Fierro JLG: Soybean oil epoxidation with hydrogen peroxide using an amorphous Ti. $\mathrm{SiO}_{2}$ catalyst. Green Chem 2004, 6:330-334.

29. Törnvall U, Orellana-Coca C: Stability of immobilized candida antarctica lipase B during chemo-enzymatic epoxidation of fatty acids. Enzym Microb Technol 2007, 40:447-451.

30. Mungroo R, Pradhan NC, Goud W, Dalai AK: Epoxidation of canola oil with hydrogen peroxide catalyzed by acidic ion exchange resin. J Am Oil Chem Soc 2008, 85:887-896.

31. Abdullah BM, Salimon J: Epoxidation of vegetable oils and fatty acids: catalysts, methods and advantages. J App/ Sci 2010, 10(15):1545-1553.

32. Orellana-Coca C, Adlercreutz D, Andersson MM, Mattiasson B, Hatti-Kaul R: Analysis of fatty acid epoxidation by high performance liquid chromatography coupled with evaporative light scattering detection and mass spectrometry. Chem Phys Lipids 2005, 135:189-199.

33. Du G, Tekin A, Hammond EG, Woo LK: Catalytic epoxidation of methyl linoleate. J Am Oil Chem Soc 2004, 81:477-480

34. Salimon J, Salih N, Abdullah BM: Production of chemoenzymatic catalyzed monoepoxide biolubricant: optimization and physicochemical characteristics. J Biomed Biotechnol 2012, 2012:693848.

35. Lozada Z, Suppes GJ, Tu Y-CH, Hsieh F-H: Soy-based polyols from oxirane ring opening by alcoholysis reaction. J Appl Polym Sci 2009, 113:2552-2560.

36. Von V: Heterogeneously Catalyzed Reactions with Vegetable Oils: Epoxidation and Nucleophilic Epoxide Ring-Opening with Alcohols. Aus Medellín, Colombia: M. Sc-Chemisch Ingenieur Luis Alberto Rios; 2002.

37. Schuster H, Rios LA, Weckes PP, Hoelderich WF: Heterogeneous catalysts for the production of new lubricants with unique properties. App/ Catal A Gen 2008, 348:266-270

38. Salimon J, Abdullah BM, Yusop RM, Salih N: Synthesis and optimization ring opening of monoepoxide linoleic acid using $p$-Toluenesulfonic acid. SpringerPlus 2013, 2013(2):429.

39. Salimon J, Abdullah BM, Salih N: Improvement of physicochemical characteristics of monoepoxide linoleic acid ring opening for biolubricant base oil. J Biomed Biotechnol 2011, 2011:196565.

40. Campanella A, Baltanás MA: Degradation of the oxirane ring of epoxidized vegetable oil in liquid-liquid systems: II. Reactivity with solvated acetic acid and peracetic acids. Lat Am Appl Res 2005, 35:211-216.

41. Campanella A, Baltana's MA: Degradation of the oxirane ring of epoxidized vegetable oils in a liquid-liquid-solid heterogeneous reaction system. Chem Eng Process 2007, 46:210-221.

42. Lathi PS, Mattiasson B: Green approach for the preparation of biodegradable lubricant base stock from epoxidized vegetable oil. Appl Catal B Environ 2007, 69:207-212. 
43. Christie WW: Lipid Analysis. 3rd edition. Bridgwater, UK: The Oily Press; 2002. in press.

44. Dörmó N, Bélafi-Bakó K, Bartha L, Ehrenstein U, Gubicza L: Manufacture of an environmental-safe biolubricant from fusel oil by enzymatic esterification in solvent-free system. Biochem Eng J 2004, 21:229-234.

45. Moser BR, Sharma BK, Doll KM, Erhan SZ: Diesters from oleic acid: synthesis, low temperature properties, and oxidative stability. J Am Oil Chem Soc 2007, 84:675-680.

46. Uosukainen E, Linko Y-Y, Lämsä M, Tervakangas T, Linko P: Transesterification of trimethylolpropane and rapeseed oil methyl ester to environmentally acceptable lubricants. J Am Oil Chem Soc 1998, 75:1557-1563.

47. Yunus R, Fakhru'l-Razi A, Ooi TL, lyuke SE, Idris A: Development of optimum synthesis method for transesterification of palm oil methyl esters and trimethylolpropane to environmentally acceptable palm oil-based lubricant. J Oil Palm Res 2003, 15:35-41.

48. Linko Y-Y, Tervakangas T, Lämsä M, Linko P: Production of trimethylolpropane esters of rapessed oil fatty acids by immobilized lipase. Biotechnol Technol 1995, 11:889-892.

49. Eychenne V, Mouloungui Z, Gaset A: Total and partial eructate of pentserythritol. Infrared spectroscopy study of relationship between structure, reactivity and thermal properties. J Am Oil Chem Soc 1998, 75:293-300.

50. Cryglewicz S, Piechocki W, Cryglewicz G: Preparation of polyol esters on vegetable and animal fats. Bioresour Technol 2003, 87:35-39.

51. Salih N, Salimon J, Yousif E, Abdullah BM: Biolubricant basestocks from chemically modified plant oils: ricinoleic acid based-tetraesters. Chem Centr J 2013, 2013(7):128.

52. Salimon J, Abdullah BM, Salih N: Diesters biolubricant base oils: synthesis, optimization, characterization and physicochemical characteristics. Int J Chem Eng 2012, 2012:896598.

53. Abdullah BM, Salimon J: Optimization of process parameters for diesters biolubricant using D-optimal design. World Acad Sci Eng Technol 2011, 5(8):688-696. International Science Index 56.

doi:10.1186/1752-153X-8-16

Cite this article as: Salimon et al:: Synthesis, reactivity and application studies for different biolubricants. Chemistry Central Journal 2014 8:16.

\section{Publish with ChemistryCentral and every scientist can read your work free of charge \\ "Open access provides opportunities to our colleagues in other parts of the globe, by allowing anyone to view the content free of charge." \\ W. Jeffery Hurst, The Hershey Company. \\ - available free of charge to the entire scientific community \\ - peer reviewed and published immediately upon acceptance \\ - cited in PubMed and archived on PubMed Central \\ - yours - you keep the copyright \\ Submit your manuscript here: \\ http://www.chemistrycentral.com/manuscript/<smiles>c1ccccc1</smiles> \\ Chemistry Central}

